\title{
Geographical variation in mortality from ischaemic heart disease in England and Wales
}

\author{
R. R. WEST \\ From the Department of Community Medicine, Welsh National School of Medicine
}

SUMMARY Analysis of the proportional mortality attributed to ischaemic heart disease, adjusted for age, reminds us that many of the well known geographical, environmental, social, and economic variations within England and Wales are not disease specific.

Geographical variations in death rates within England and Wales have been known since the early issues of the Registrar General's annual reports by William Farr (1838-82). For most diseases the standard mortality ratios (SMRs) are lower in the south and east and higher in the north and west (Registrar General, 1971-76). Recently particular attention has been paid to the regional variations in ischaemic heart disease (IHD) mortality, the twentieth century epidemic of the affluent nations. Many epidemiologists have studied the geographical variations within England and Wales, within other countries and internationally for clues on the aetiology of the disease. Morris et al. (1961) examined the 1951 decennial supplement data on area mortality for 83 county boroughs in England and Wales (excluding London) and found significant negative associations between age specific mortality from cardiovascular diseases and the total hardness of water supplies, as had been reported in other countries, but also significant negative associations between mortality from all causes and total hardness. Since then many further papers have reported on geographical variations within countries (reviewed by Heyden, 1976, and in British Medical Journal, 1976). The principal factors with which age specific death rates and SMRs have been found to be associated in England and Wales are temperature, rainfall, socioeconomic index, water calcium, latitude, and domestic air pollution. Epidemiological studies may help in the elucidation of disease aetiology if they can identify causal associations. However, it is necessary, firstly to identify clearly just what is in the death rate that demonstrates variation associated with socioenvironmental factors and, secondly, to establish whether the associations with socioenvironmental factors are causal.

In comparisons of disease specific mortality whether it be by region, occupational group, or social class, a 'high mortality area' is often identified by a raised SMR. The SMR may be raised (relative to the standard population) in two ways, either because more of the study population die of that disease instead of other diseases than in the standard population, or because people in the study population die younger of that disease (and possibly also of other diseases) than in the standard population. Relating this to the problem of geographical variation in IHD mortality we shall consider the two hypotheses:

(1) That in areas of 'high IHD mortality' there are proportionately more IHD deaths than in England and Wales as a whole, or

(2) That in areas of 'high IHD mortality' the IHD deaths are at a younger age than in England and Wales as a whole.

This approach attempts to elucidate whether the well known and frequently observed geographical variations in IHD SMRs are principally because of variations in disease specific mortality (the proportion of the population that suffer deaths from this disease as distinct from other diseases) or to variations in the age at which populations succumb to this disease (and to other diseases). The associations between statistics of IHD mortality and socioenvironmental variables are also studied, in consideration of how the latter may be causally associated with mortality.

\section{Methods}

The numbers of deaths by age and sex are listed for 15 hospital regions of England and Wales for 50 diseases of the B list in the Statistical Review (Registrar General, 1971-76). From these data it is possible to determine for each hospital region the age specific death rates for IHD (ICD 8th revision, codes 410-414 World Health Organisation, 1967), and for all deaths, and to calculate the IHD proportional 
mortalities. There are several ways of expressing the IHD proportional mortality. Table 1 gives a sample of proportional mortality ratios (PMRs) for males for England and Wales and for the hospital regions with highest and lowest male SMRs for IHD mortality in 1973. The conventional ratio of disease specific deaths to deaths from all causes, irrespective of age, is listed in (a), six age specific proportional mortality ratios in (b), and the age standardised proportional mortality ratio (SPMR) in (c).

Table 1 Proportional mortality ratios (PMRs) for ischaemic heart disease, males 1973

\begin{tabular}{|c|c|c|c|}
\hline \multirow{2}{*}{ Mortality } & \multicolumn{2}{|c|}{ Hospital region } & \multirow{2}{*}{$\begin{array}{l}\text { England } \\
\text { and Wales }\end{array}$} \\
\hline & Newcastle & East Anglia & \\
\hline $\begin{array}{c}\text { From ischaemic heart disease } \\
\text { (a) All age PMR } \\
\text { (b) PMR aged } 35-44 \\
\text { aged } 45-54 \\
\text { aged } 55-64 \\
\text { aged } 65-74 \\
\text { aged } 75+\end{array}$ & $\begin{array}{l}0.317 \\
0.363 \\
0.396 \\
0.357 \\
0.315 \\
0.269\end{array}$ & $\begin{array}{l}0.313 \\
0.297 \\
0.371 \\
0.340 \\
0.317 \\
0.268\end{array}$ & $\begin{array}{l}0.313 \\
0.286 \\
0.396 \\
0.358 \\
0.320 \\
0.258\end{array}$ \\
\hline $\begin{array}{l}\text { (c) Age standardised PMR } \\
\text { (d) SMR } \\
\text { (e) From all causes SMR }\end{array}$ & $\begin{array}{l}101 \cdot 3 \\
119 \\
115\end{array}$ & $\begin{array}{l}99 \cdot 7 \\
87 \\
89\end{array}$ & $\begin{array}{l}100 \\
100 \\
100\end{array}$ \\
\hline
\end{tabular}

This last is calculated by comparing the observed numbers of deaths expected on the basis of England and Wales age specific PMRs and the local numbers of deaths from all causes within each age group. The derivation is very similar to that of the standardised mortality ratio. The former for IHD mortality among males in Cardiff using England and Wales as the standard is given by:

SMR =

$$
\Sigma \text { IHD deaths (Cardiff) }
$$

$\overline{\sum \frac{\text { alive men (Cardiff) }}{\text { alive men (E and } W)} \text { IHD deaths (E and W) }}$

where the summation is over $i$ age groups.

The standardised proportional mortality is also a ratio given by:

SPMR $=$

$\frac{\Sigma \text { IHD deaths (Cardiff) }}{\sum \frac{\text { IHD deaths (E and } W)}{\text { all deaths (E and } W)} \text { all deaths (Cardiff) }}$

For comparison the disease specific SMR (d) and the all cause SMR (e) are also listed. SPMRs have been calculated for males and females separately for the $\mathbf{1 5}$ hospital regions of England and Wales.

For further analysis of the geographical variation within England and Wales we turn again to the county and London boroughs. The numbers of IHD deaths (ICD codes 410-414) by sex, age, and month for each of 115 county and London boroughs for the years 1969-71 were prepared by the Office of Population Censuses and Surveys $\underset{\infty}{\stackrel{D}{~}}$ (OPCS) for our previous study (West and Lowe, O 1976) and the numbers of deaths from all causes by age and sex for three years have been provided by OPCS for this study. Age specific PMRs and SPMRs have been calculated for both sexes $\vec{F}$ separately for the 115 county and London boroughs. The associations have been examined $\frac{C}{0}$ between these new statistics of relative IHD $\overline{\bar{n}}$ mortality for the years 1969-71 and temperature, $\overparen{\nabla}$ rainfall, and socioeconomic index, the three socioenvironmental variables found to be highly os significantly associated with IHD mortality (age $\overrightarrow{0}$ specific or SMR) in previous studies (Crawford et al., 1968; West et al., 1973; West and Lowe, 1976). $\vec{\sigma}^{\circ}$ In calculating the first order correlation coefficients $\frac{\widehat{D}}{\partial}$ each town has been weighted according to its total $\stackrel{\rho}{子}$ (1971 census) population, to make allowances for $\dot{\omega}$ the considerable variation in size of towns. Finally the correlation coefficients between these is statistics of proportional IHD mortality and water or calcium have been calculated for the larger county boroughs using Gardner's water calcium measurg- ments (Gardner et al., 1969) and a new set of water calcium measurements (Elwood et al., 197क्ठि) in very much the same towns.

\section{Results}

In Table 1 three different expressions of IH proportional mortality are given and for comparisơํ응 the SMRs for IHD deaths and for all causes of death. Differences between regions of the allo age PMRs could reflect differences in the age distributions as well as differences in the proportional mortality, since the proportion of $\overrightarrow{\hat{O}}$ IHD deaths is not invariate with age: the maximum 3 IHD proportional mortality for males in England and Wales is at about age 50 years. The age specific PMRs and SPMRs should be independent of the age structure of study populations. It can be $\frac{\Gamma}{-}$ seen from Table 1 that the deviations from the standard (England and Wales) are less for these 3 . measures of PMR than for SMR. In the Newcastle hospital region (highest male IHD SMR of 119 in 1973) the all age PMRs and the SPMRs are onlyo $1 \%$ more than the England and Wales values and the age specific PMRs are raised only for thoseo aged 75 years and over $(4 \%)$ and for those aged $35-44$ years $(27 \%)$, but the latter account for fewero than $2 \%$ of IHD deaths. Similarly in the Eastr Anglian hospital region (lowest SMR) the PMRsN are close to those of England and Wales ranging $\omega$ between $94 \%$ of the England and Wales value for the $45-54$ age specific ratio and $104 \%$ for the $35-44$ age specific ratio. Although the heart diseases? 
SMRs for the Newcastle and East Anglia hospital regions differ widely, the proportional mortalities (SPMR) are very close to 100 (the England and Wales standard); the proportions of all deaths attributed to IHD are very similar in the two regions. The difference between these two regions with respect to male IHD mortality is that deaths occur at younger ages in the Newcastle region than in the East Anglian region (and deaths from other causes occur at younger ages in Newcastle than in East Anglia also).

In Table 2 the SPMRs are compared with the SMRs for the 15 hospital regions of England and Wales (total population 49 million). For males the coefficient of variation of SMR is $11 \%$, while that of SPMR is less than $4 \%$ and those of the age specific ratios are also small (4-5\%), except for those aged $35-44$ years $(12 \%)$, but that age group accounts for fewer than $2 \%$ of all male IHD deaths.

Table 2 Mortality from ischaemic heart disease in 15 hospital regions of England and Wales, 1973

\begin{tabular}{|c|c|c|c|c|}
\hline \multirow[t]{2}{*}{ Hospital region } & \multicolumn{2}{|c|}{$\begin{array}{l}\text { Standardised } \\
\text { mortality ratios }\end{array}$} & \multicolumn{2}{|c|}{$\begin{array}{l}\text { Age standardised } \\
\text { proportional } \\
\text { mortality ratios* }\end{array}$} \\
\hline & Males & Females & Males & Females \\
\hline $\begin{array}{l}\text { Newcastle } \\
\text { Leeds } \\
\text { Sheffield } \\
\text { East Anglia } \\
\text { North-west London } \\
\text { North-east London } \\
\text { South-east London } \\
\text { South-west London } \\
\text { Wessex } \\
\text { Oxford } \\
\text { South West } \\
\text { Wales } \\
\text { Birmingham } \\
\text { Manchester } \\
\text { Liverpool }\end{array}$ & $\begin{array}{r}119 \\
113 \\
99 \\
87 \\
90 \\
95 \\
93 \\
87 \\
93 \\
89 \\
94 \\
114 \\
98 \\
113 \\
109\end{array}$ & $\begin{array}{r}120 \\
119 \\
99 \\
86 \\
89 \\
86 \\
95 \\
90 \\
95 \\
93 \\
95 \\
111 \\
97 \\
111 \\
109\end{array}$ & $\begin{array}{r}101 \\
108 \\
98 \\
100 \\
98 \\
99 \\
100 \\
95 \\
104 \\
100 \\
104 \\
104 \\
94 \\
102 \\
95\end{array}$ & $\begin{array}{r}110 \\
116 \\
97 \\
93 \\
93 \\
91 \\
100 \\
94 \\
101 \\
101 \\
105 \\
98 \\
95 \\
104 \\
100\end{array}$ \\
\hline
\end{tabular}

*Expected IHD deaths on basis of England and Wales age specific proportional mortality and local age specific all causes mortality.

There is no association between SPMR and SMR for males in the 15 hospital regions. For females the coefficient of variation of SPMR $(7 \%)$ is larger than for males but is still significantly smaller than for SMR (11\%). The coefficients of variation are larger only for the age specific PMRs of the younger age groups (for women aged $45-54$ years it is $18 \%$, but that age group accounts for only $2 \%$ of all female IHD deaths). There is a significant positive association for females between SPMR and SMR and between age specific PMRs and SMR in the 15 hospital regions.

Since the variation between regions in SMR is approximately twice that in SPMR it is likely that approximately half the variation in SMR is variation in age at death and only half is variation in the proportion of deaths that are attributed to IHD: in other words, there is a variation in mortality for all causes that parallels the variation in IHD mortality. This is not surprising since the well-known gradient of mortality in England and Wales (from south and east to north and west) is not restricted to deaths from IHD alone. A comparison of rank order of IHD mortality of the hospital regions indicated by SMR and SPMR shows that four regions are ranked much less favourably on the latter statistic, East Anglia (M), Wessex (M and F), Oxford (M), and South West (M) and that three regions are ranked much more favourably Sheffield (M), Birmingham ( $M$ and $F$ ), and Liverpool (M).

The associations between statistics of proportional IHD mortality in 115 county and London boroughs (total population 21.5 million) and three principal socioenvironmental factors found to be associated with IHD mortality in previous studies have been calculated. Males and females have been analysed separately because in the inter-regional analyses PMRs for males demonstrate small variance and no association with SMR, while for females the PMRs demonstrated larger variances and significant associations with SMR. The results for SPMR are summarised in Table 3 and those for SMR are

Table 3 Mortality from ischaemic heart disease and temperature, rainfall, and socioeconomic index in 115 county and London boroughs 1969-71; first order correlation coefficients weighted by populations

\begin{tabular}{|c|c|c|c|}
\hline & Temperature & Rainfall & $\begin{array}{l}\text { Socioeconomic } \\
\text { index }\end{array}$ \\
\hline $\begin{array}{l}\text { Age standardise } \\
\text { proportional } \\
\text { mortality ratio } \\
\text { Males } \\
\text { Females }\end{array}$ & $\begin{array}{c}0.05 \\
-0.25 * *\end{array}$ & $\begin{array}{l}0.15 \\
0.17\end{array}$ & $\begin{array}{l}0.36^{* * * *} \\
-0.10\end{array}$ \\
\hline $\begin{array}{l}\text { Standardised } \\
\text { mortality ratio } \\
\text { Males } \\
\text { Females }\end{array}$ & $\begin{array}{l}-0 \cdot 45 * * * \\
-0 \cdot 51 * * *\end{array}$ & $\begin{array}{l}0 \cdot 46^{* * * *} \\
0 \cdot 38^{* * *}\end{array}$ & $\begin{array}{l}-0.45^{* * * *} \\
-0.42^{* * *}\end{array}$ \\
\hline
\end{tabular}

included for comparison, although SMRs were examined in previous studies (West et al., 1973; West and Lowe, 1976). The correlation coefficients relating SPMR to each socioenvironmental factor are much smaller than those relating SMR to the same socioenvironmental factor. The only significant associations with SPMR are the socioeconomic index for males $(P<0.001)$ and temperature for females $(P<0.01)$, while the SMR is highly associated with all three for both sexes. However, the association between male SPMR and socioeconomic index is interesting since it is positive, while that 
between male SMR and socioeconomic index is negative. In other words the all-cause SMR is even more strongly associated negatively with socioeconomic index than is the IHD SMR and towns with low socioeconomic indices have high SMRs for both IHD mortality and mortality from all causes but a low proportion of deaths attributed to IHD. The male SPMRs are associated with neither temperature nor rainfall. For females the significant association between mean environmental temperature and SPMR is negative, just as is the association between temperature and SMR, but the association is considerably weaker. There are no associations between female SPMRs and rainfall and socioeconomic index.

The age specific PMRs are highly correlated with the SPMR for the 115 county and London boroughs except for the youngest age groups where the numbers of deaths in the three years 1969-71 per borough were small. The correlation coefficients relating these other statistics of proportional IHD mortality to the SPMR are summarised as follows: for males aged 35-44 years $r=0 \cdot 35,45-54 r=0 \cdot 57$, $55-64 \mathrm{r}=0.74,65-74 \mathrm{r}=0.89$ and $75+r=0.77$ and for females aged 45-54 years $r=0.25,55-64 \mathrm{r}=$ $0.61,65-74 \mathrm{r}=0.79,75-84 \mathrm{r}=0.91$ and $85+$ $=0.70$. The associations between age-specific PMRs for both sexes and temperature, rainfall, and socioeconomic index were studied and they show patterns of weak association similar to those of the SPMR.

Water calcium measurements for 61 large county boroughs, including only three from the Greater London area were published by Gardner et al. (1969) in their study of mortality and its association with socioenvironmental indices. Since their study, East Ham and West Ham (in London) have been redefined, parts being included in the new borough of Newham. The relationship between SPMR and four socioenvironmental variables (including water calcium) have been investigated by population weighted correlation analysis for those 60 boroughs (total population 12.5 million). Elwood et al. (1977) have measured water calcium and other trace elements in almost the same towns (including only Croydon from the Greater London area) and the correlation analysis has been repeated for these 61 towns (total population $12 \cdot 2$ million). The correlation coefficient relating SPMR and four socioenvironmental variables including water calcium are summarised in Table 4. It would appear that the geographical variation of proportional IHD mortality in these smaller samples of towns (mostly outside London) is quite independent of water calcium. For both these smaller samples of towns the SMRs for IHD were strongly associated
Table 4 Age standardised proportional mortality from ischaemic heart disease and temperature, rainfall, socioeconomic index, and water calcium in 60 (61) large county boroughs 1969-71, first order correlation coefficients weighted by population

\begin{tabular}{|c|c|c|c|c|}
\hline $\begin{array}{l}\text { Age standardised } \\
\text { proportional } \\
\text { mortality ratio }\end{array}$ & Temperature & Rainfall & $\begin{array}{l}\text { Socioeconomic } \\
\text { index }\end{array}$ & $\begin{array}{l}\text { Water } \\
\text { calcium }\end{array}$ \\
\hline $\begin{array}{l}\text { Males } \\
60 \text { boroughs } \\
61 \text { boroughs }\end{array}$ & $\begin{array}{l}0 \cdot 18 \\
0 \cdot 26^{*}\end{array}$ & $\begin{array}{l}0 \cdot 21 \\
0 \cdot 20\end{array}$ & $\begin{array}{l}0 \cdot 30^{*} \\
0 \cdot 33^{*}\end{array}$ & $\begin{array}{l}0.00 \\
0.04\end{array}$ \\
\hline $\begin{array}{l}\text { Females } \\
60 \text { boroughs } \\
61 \text { boroughs }\end{array}$ & $\begin{array}{l}-0.13 \\
-0.07\end{array}$ & $\begin{array}{l}0.06 \\
0.05\end{array}$ & $\begin{array}{l}-0.04 \\
-0.04\end{array}$ & $\begin{array}{l}0.03 \\
0.06\end{array}$ \\
\hline
\end{tabular}

*Significant at P -0.05 , all others not significant.

with water calcium (population weighted coefficients $r=-0.59$ for 60 towns and $r=-0.63$ for 61 towns $\stackrel{\rho}{)}$ for males; $r=-0.31$ for 60 towns and $r=-0.32 \omega$ for 61 towns for females) but the proportional is mortality analysis shows that the association was is not disease specific.

\section{Discussion}

The geographical variation in mortality withi傮 England and Wales has been known for a long time but in recent years several epidemiological studies $\mathbb{\perp}$ have concentrated on heart disease mortality an $\overrightarrow{0}$ have sought through its geographical variation. $\exists$ for causal associations. Crawford et al. (1968) reporte significant associations with water calcium, sociă factor score, and latitude for mortality from all causes; although their research was directed towards study of cardiovascular disease they did $\stackrel{\circ}{\mathbb{D}}$ state that the strongest association (with water hardness) was not disease specific. The mechanisms by which socioenvironmental variables may be causally associated with general mortality are unlikely to be of the same nature as mechanisms by which socioenvironmental variables may be causally associated with the incidence (and mortality) of specific disease.

Stocks (1973) examined the proportional mortality for cancer and cardiovascular disease and showed that there was no association with classification of water hardness. This study confirms that the geographical gradient in IHD mortality parallels $\rightarrow$ a similar geographical gradient in mortality from all causes. The comparison by hospital regions of $N$ proportional IHD mortality with standardised IHD mortality shows that the former varies from 0 the England and Wales value only approximately ${ }_{\omega}^{N}$ half as much as does the latter. The principalo difference between Newcastle (hospital region)o with the highest SMR for men and East Anglia $\mathbb{\varnothing}$ with the lowest (Table 1) must be in ages at $\stackrel{\odot}{+}$ 
which deaths occur both from IHD and also from other causes, since the SMPRs were very close to 100 for both regions. Large variations between regions or between towns in SMR accompanied by small variations in SPMR imply large differences in age at death (from IHD and from other causes) or in susceptibility to death and small differences in the proportion incurring death from IHD and possibly small differences in the proportion suffering the disease.

Secondly, in the analysis of mortality in county and London boroughs, the significant associations between SPMR and four socioenvironmental variables were few compared with those between SMR and the same four variables. The IHD proportional mortality in boroughs of England and Wales is not associated with either rainfall or water calcium. Although previous studies (Morris et al., 1961; Crawford et al., 1968; Gardner et al., 1969; West et al., 1973) (and this study) have shown that these two climatic or environmental factors may be associated with IHD SMR, the associations are clearly not disease specific. These environmental factors could affect SMR without affecting PMR only by influencing the age at death (but they must be also influencing the age at death from other causes in a similar manner).

The associations with temperature differ between the sexes. For men the environmental temperature is negatively correlated with SMR but not associated with SPMR. Therefore this climatic variable (as rainfall and water calcium) could influence SMR (without influencing SPMR) only by influencing the age at death. For women the difference between SMR and SPMR is not so marked: environmental temperature is negatively associated with SMR and to a lesser degree also with SPMR. It seems likely that this climatic variable partly affects the age at death of women dying of IHD (and to a lesser extent of women dying of other causes) and partly affects the proportion of women dying of IHD.

A significant positive association between the IHD proportional mortality and socioeconomic index was also found only for men, while the IHD SMR is negatively associated with socioeconomic index. This implies that low socioeconomic circumstances increase the risk for men of early death from IHD but that they increase the risk even more of early death from other causes. For women the IHD proportional mortality is not associated with socioeconomic index and for that factor to affect SMR (without affecting SPMR) it must act through the age at death, just as the climatic factors.
We have, therefore, a large geographical variation within England and Wales in IHD SMR but a smaller variation in SPMR. The former is highly associated with climatic variables, while the latter is almost unassociated and it is suggested that the factors (in climate) which influence the SMR must be factors which influence the age at death for all causes of death as well as for IHD. It is no new observation that climatic factors are associated with death: very strong negative associations between death rates and temperature in seasonal variations have been reported in several countries (Rose, 1966; Anderson and le Riche, 1970; Bull, 1973) and the additional effect of snowfall has also been included in the USA (Rogot and Padgett, 1976). The effect of temperature on mortality in seasonal variation is not restricted to IHD (Anderson and le Riche, 1970). In seasonal variation adverse environments (principally cold temperatures in winter) cause death several months earlier than would occur on age/degenerative disease criteria unmodified by climate and conversely mild comfortable environments (of summer months) allow postponement of deaths, principally determined by age/degenerative disease criteria. In previous papers we have referred to a few of many published reports of associations between physiological measurements and environmental temperature in laboratory, in seasonal and in geographical studies (for example Neill et al. (1974) showed how cold can induce angina, increase heart rate, blood flow, blood pressure, and myocardial oxygen consumption in healthy subjects and more easily in patients with heart disease), and we have suggested that the same mechanisms explain much of the geographical variation in SMR for IHD mortality (West et al., 1973; West and Lowe, 1976). This study shows that there is little association between proportional mortality and climatic factors; the latter do not discriminate by disease type but effect early death from all causes in the same sense, although not necessarily to the same degree (Anderson and le Riche, 1970). Finally, the socioeconomic index of 115 county and London boroughs is positively associated with SPMR for men while being negatively associated with SMR. This observation may be interpreted according to the same model: low socioeconomic circumstances are associated with early death from IHD, but more so with early death from all causes, or low socioeconomic circumstances are even more likely to cause early death among males through the other major diseases-bronchitis and pneumonia and the cancers. 


\section{Conclusion}

In England and Wales the mortality from ischaemic heart disease follows the same pattern of variation as those of most other diseases (low in the south and east and high in the north and west). In seeking the cause of this variation it is important to establish what it is that varies and then to consider what could cause that variation. It is suggested that the foregoing analysis shows a large and important geographical variation in age at death, which is reflected in SMRs and age specific death rates but only a small variation in SPMRs or age specific proportional mortality ratios (Table 2 ). Past studies have shown that the SMR and age specific mortality rates for IHD are associated with temperature, rainfall, and socioeconomic index (West et al., 1973; West and Lowe, 1976), and latitude, water calcium, social factor score, and domestic air pollution (Crawford et al., 1968), but this study shows that the proportion of deaths attributed to IHD is not associated with temperature (for men) or rainfall or water calcium. It would appear therefore that these climatic and environmental factors do not cause IHD, but rather that they effect early death from IHD (and from other causes). There is very little association between previously isolated socioenvironmental 'risk factors' of IHD mortality and the proportion of deaths attributed to IHD; or in other words, these socioenvironmental 'risk factors' are not disease specific. It follows therefore that these 'risk factors' are unlikely to be affecting causally a geographical variation in incidence of IHD in England and Wales. The significant geographical differences within England and Wales are differences in mortality and they are largely differences in age at death, irrespective of cause of death. The public health measures should not be directed towards eradicating 'an IHD specific toxin' in the England and Wales environment, since mortality from other causes demonstrates similar associations with socioenvironmental variables, but should be directed towards alleviating early death from all causes (including IHD) by modifying the environmental 'micro climate' and improving socioeconomic circumstances.

I am grateful to the Office of Population Censuses and Surveys for preparing tables of ischaemic heart disease mortality and for copies of tables of all cause mortality and to Dr P. C. Elwood for water calcium data before publication.

Reprints from Dr R. R. West, Department of Community Medicine, Welsh National School of Medicine, Heath Park, Cardiff CF4 4XN.

\section{References}

Anderson, T. W., and le Riche, W. H. (1970). Cold weather and myocardial infarction. Lancet, 1, 291-296.

British Medical Journal (1976). Editorial: Hard water story. No recommendations. British Medical Journal, 2, 389-390.

Bull, G. M. (1973). Meteorological correlates with myocardial and cerebral infarction and respiratory disease. British Journal of Preventive and Social Medicine, 27, 108-113.

Crawford, M. D., Gardner, M. J., and Morris, J. N. (1968). Mortality and hardness of local water supplies. Lancet, 1, 827-31.

Elwood, P. C., St Leger, A. S., and Morton, M. (1977). Mortality and the concentration of elements in tap water in county boroughs in England and Wales. British Journal of Preventive and Social Medicine, 31, 178-182.

Farr, W. (1838-1882). Annual Reports of Registrar General of Births, Deaths and Marriages in England, 1837-80. HMSO: London.

Gardner, M. J., Crawford, M. D., and Morris, J. N. (1969). Patterns of mortality in middle and early old age in the county boroughs of England and Wales.o British Journal of Preventive and Social Medicine, 230 133-140.

Heyden, S. (1976). Hard facts behind the hard wate theory and ischaemic heart disease. Journal of Chronif Diseases, 29, 149-57.

Morris, J. N., Crawford, M. D., and Heady, J. A. (1961) Hardness of local water supplies and mortality from cardiovascular disease. Lancet, 1, 860-862.

Neill, W. A., Duncan, D. A., Kloster, F., and Mahle? D. J. (1974). Response of coronary circulation to cutaneous cold. American Journal of Medicine, 56, 471-476.

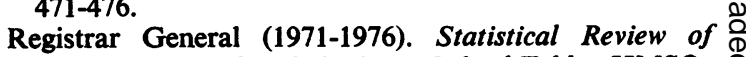
England and Wales 1969-73. I. Medical Tables. HMSO: London.

Rogot, E., and Padgett, S. J. (1976). Association of $\exists$ coronary and stroke mortality with temperature and snowfall. American Journal of Epidemiology, 103, 565-575.

Rose, G. (1966). Cold weather and ischaemic heart disease. British Journal of Preventive and Social Medicine, 20, 97-100.

Stocks, P. (1973). Mortality from cancer and cardiovascular disease in the county boroughs of England and Wales classified according to the sources and hardness of their water supplies 1958-67. Journal of 을 Hygiene, 71, 237-252.

West, R. R., Lloyd, S., and Roberts, C. J. (1973). $\frac{7}{0}$ Mortality from ischaemic heart disease: Association with weather. British Journal of Preventive and Social $N$ Medicine, 27, 36-40.

West, R. R., and Lowe, C. R. (1976). Mortality from $N$ ischaemic heart disease: Intertown variation and its association with climate in England and Wales. F International Journal of Epidemiology, 5, 195-201.

World Health Organisation (1967). International Classi- $\frac{0}{\Phi}$ fication of Diseases, 8th revision. WHO: Geneva. 